\title{
Educación patrimonial y fotografía estereoscópica: intervención didáctica
}

\author{
Heritage Education and Stereoscopic Photography: Didactic Proposal \\ Educació patrimonial i fotografia estereoscòpica: intervenció didàctica
}

\author{
Jordi Ferrer-Peris ${ }^{\circledR}$, Juan Carlos Colomer-Rubio*® \\ Universitat de València \\ *Autor para correspondencia: juan.colomer@uv.es (Juan Carlos Colomer-Rubio)
}

Recibido: 12/03/2019 | Aceptado: 03/05/2019 | Publicado: 24/06/2019

Cómo citar: Ferrer-Peris, J., y Colomer-Rubio, J. C. (2019). Educación patrimonial y fotografía estereoscópica: intervención didáctica. Research in Education and Learning Innovation Archives, 22,45-57. 10.7203/realia.22.15342

Copyright: El/La Autor/a. Open Access: Este es un artículo de acceso abierto distribuido bajo los términos de la licencia Creative Commons AttributionNonCommercial-ShareAlike 4.0 International (CC BY-NC-SA 4.0)

\footnotetext{
Financiación: Esta investigación forma parte del proyecto "Las representaciones sociales de los contenidos escolares en el desarrollo de las competencias docentes" (PGC2018-094491-B-C32) financiado por el Ministerio de Ciencia, Innovación y Universidades.
}

\begin{abstract}
RESUMEN: La inserción de la tecnología digital para el trabajo del patrimonio material e inmaterial puede convertirse en una herramienta creativa que refuerce el papel del maestro/a como agente educador del patrimonio local, en la línea de lo sugerido en el Plan Nacional de Educación y Patrimonio (PNEyP). Este tipo de recursos permite el desarrollo de herramientas que mejoran la interpretación de los entornos patrimoniales y los acercan al alumnado. En esta propuesta de innovación se expone una intervención didáctica original realizada con discentes de sexto de Educación Primaria en el entorno del Castell de Marinyén (Benifairó de la Valldigna, Valencia); en ella se utilizan la fotografía estereoscópica o esférica y la hipótesis de reconstrucción. Esta propuesta aúna investigación sobre el entorno inmediato, la utilización de tecnologías digitales y el uso de la imagen como documento de investigación. Ello ha permitido plantear una vía de introducción de los medios tecnológicos en educación patrimonial por medio de unos recursos actualizados, sencillos y accesibles que permiten la realización de investigaciones concretas y el trabajo de contenidos de diferentes áreas de conocimiento (Ciencias Sociales, Ciencias Naturales...). En conclusión, se vienen a suplir los defectos que la educación patrimonial ha tenido en su inserción en el sistema educativo, ampliando su tratamiento en el aula, así como su disposición dentro del currículo escolar.
\end{abstract}

PALABRAS CLAVE: Educación patrimonial; Entorno local; Fotografía esférica; Fotografía estereoscópica; Innovación; Tecnología educativa

ABSTRACT: The introduction of digital technology for the work of tangible and intangible heritage can become a creative tool that reinforces the role of the teacher as an educator of local heritage, in line with what is suggested in the Plan Nacional de Educación y Patrimonio (PNEyP). In addition, this type of resources allow the development of tools that improve the interpretation of the patrimonial environments and bring them closer to the students. Our proposal is an original didactic intervention made with sixth grade students of Primary Education is exposed in the environment of Castell de Marinyén (Benifairó de la Valldigna, Valencia) through the use of stereoscopic or spherical photography and the hypothesis of reconstruction. This activity combines research on the immediate environment, the digital technologies and the use of image as a research document, which has made it possible to propose the technological means in patrimonial education by means of updated, simple and accessible resources that allow the realization of concrete investigations and the work of contents of different areas of knowledge. In conclusion, the defects that the patrimonial education has had in its insertion in the educational system, extending its treatment in the classroom, as well 
as its disposition within the school curriculum.

KEYWORDS: Heritage education; Local environment; Spherical photography; Stereoscopic photography; Innovation; Educative technology

RESUM: La inserció de la tecnologia digital per al treball del patrimoni material i immaterial pot esdevenir una eina creativa que reforce el paper del mestre/a com a agent educador del patrimoni local, en la línia del que suggerit en el Pla Nacional d'Educació i Patrimoni (PNEyP). Aquest tipus de recursos permeten el desenvolupament d'eines que milloren la interpretació dels entorns patrimonials i els acosten a l'alumnat. En aquesta proposta d'innovació s'exposa una intervenció didàctica original realitzada amb discents de sisè d'Educació Primària en l'entorn del Castell de Marinyén (Benifairó de la Valldigna, València); en aquest s'utilitzen la fotografia estereoscòpica o esfèrica i la hipòtesi de reconstrucció. Aquesta és una proposta que uneix investigació sobre l'entorn immediat, la utilització de les tecnologies digitals i l'ús de la imatge com a document d'investigació. Això ha permès plantejar una via de introducció dels mitjans tecnològics en educació patrimonial per mitjà d'uns recursos actualitzats, senzills i accessibles que permeten la realització d'investigacions concretes i el treball de continguts de diferents àrees de coneixement. En conclusió, es vénen a suplir els defectes que l'educació patrimonial ha tingut en la seua inserció en el sistema educatiu, ampliant el seu tractament a l'aula, així com la seua disposició dins del currículum escolar.

PARAULES CLAU: Educació patrimonial; Entorn local; Fotografia esfèrica; Fotografia estereoscòpica; Innovació; Tecnologia educativa

Notas de aplicación práctica

Qué se sabe sobre este tema

- La fotografía estereoscópica es uno de los recursos más interesantes para el trabajo de la Educación Patrimonial en el aula y, a su vez, más desconocido para el profesorado.

\section{Qué aporta este trabajo}

- Presenta y analiza una intervención educativa original que parte del uso de la imagen digital como herramienta creativa para el trabajo del patrimonio con herramientas concretas.

\section{Implicaciones para la práctica y / o política}

- La propuesta facilita un aprendizaje completo del entorno patrimonial, aumenta la motivación del alumnado y tiene su influencia en otros sectores como el turismo o el desarrollo rural.

\section{INTRODUCCIÓN}

La sociedad actual está cada vez más inmersa en un proceso de tecnificación que invade todas las esferas del espacio público. Es esta una colectividad donde el consumo de dispositivos electrónicos (tablets, ordenadores o smartphones) así como de aplicaciones (app) está en pleno desarrollo (Castañeda, Esteve, y Adell, 2018). Dentro de esta evolución tecnológica, la creación de imágenes mediante la cámara del dispositivo móvil o el aplicativo especializado para la elaboración de imágenes 3D -equirectangulares, estereoscópicas o, como las conocemos actualmente, imágenes esféricas- ha supuesto un recurso interesante que puede ser integrado en la Educación Patrimonial empleando una determinada metodología (Calderón, 2015; Rivero y Flores, 2013).

El Patrimonio, tal y como se define actualmente es "el legado del pasado, el legado con el que convivimos y el legado que será recibido por generaciones futuras" (UNESCO, 2003, p. 3). Todo ello incluye música, bibliotecas y restos arqueológico entre otros recursos. Para garantizar la transmisión de estos bienes culturales de generación en generación, dicho patrimonio está regulado por distintas leyes, tanto estatales como autonómicas, así como por proyectos como el Plan Nacional de Educación y 
Patrimonio (a partir de ahora PNEyP) para la inserción de los nuevos modelos de enseñanza/aprendizaje y la innovación de las herramientas para su interpretación.

Pese todo, y como han destacado Pinto y Molina en su análisis sobre la educación patrimonial en los currículos de Ciencias Sociales de España y Portugal, se puede afirmar que el currículo educativo tanto en Educación Primaria como Secundaria, no menciona directamente ningún elemento del patrimonio (las fuentes destacadas son el cómic, el cine o diferentes documentos escritos) y, además, tampoco aparece el término "Patrimonio Inmaterial". Todo ello indica que este tipo de recursos no tiene cabida en el currículo educativo actual (Pinto y Molina, 2015, p. 125).

Esto desaprovecha el carácter transversal de los recursos patrimoniales (Arévalo, Bayona, y Rincón, 2015), con especial incidencia en materias como las Ciencias Sociales, donde la aplicación de recursos virtuales y aplicaciones concretas ya ha dado buenos resultados (Santacana, Martínez, López, y Grevtsova, 2015; Tamayo y Leite, 2015). Por esto, el modelo y los elementos de aprendizaje de estas asignaturas debe cambiar para dejar atrás una presentación del patrimonio como una herencia nacional que debe ser memorizada (Carretero, 2007 ; Pinto y Molina 2015 , p. 105). Para que se produzca este cambio es necesario que los docentes huyan de un aprendizaje positivista de las Ciencias Sociales y recuperen los entornos patrimoniales presentes en el currículo (Carretero, 2007 ; Pinto y Molina 2015, p. 105). El profesorado ha de liberarse de los dictados del experto para poder introducir sus propios criterios basándose en su experiencia y en el diálogo con colegas y discentes (Lisón, 2016).

Dentro de este cambio conceptual, la fotografía estereoscópica inserta en los nuevos recursos virtuales, puede ser un elemento de envergadura para introducir el patrimonio en edades tempranas y vincularlo a otras áreas sociales y a sectores como el turismo (Yovcheva, Buhalis, Gatzidis, y Elzakker, 2014). En esta línea de trabajo destacan varios estudios pioneros en diferentes áreas de conocimiento que han tenido cierta trascendencia social, como el propio proyecto Virgo (Rivero y Flores, 2013).

En relación a esto, el PNEyP tiene por función establecer unos criterios metodológicos de actuación unificada en torno a los bienes culturales y, además, elaborar algunos objetivos entre los cuales están: incorporar la Educación Patrimonial como una línea de desarrollo prioritaria en los planes estratégicos tanto del Ministerio de Educación, Cultura y Deporte como en las Comunidades Autónomas; implementar la normativa para favorecer la inclusión de los contenidos relacionados con el patrimonio y, a su vez, fomentar la creación de materiales educativos orientados a la transmisión de conceptos y valores patrimoniales (Fontal y Ibáñez, 2015, p. 19-22).

Siguiendo estos objetivos, y con la finalidad de romper la Metáfora de Booker (Gutiérrez y Hernández, 2003) mediante la imagen digital, y favorecer la adquisición de los niveles más altos de la taxonomía de Bloom (Vera, Ortega, y Burgos, 2003) por medio de la inmersión en la Realidad Virtual (VR), presentamos una intervención didáctica dentro del Castell de Marinyén (Benifairó de la Valldigna-Valencia). Esta experiencia propone utilizar determinadas herramientas tecnológicas que inciden en un trabajo holístico de la educación patrimonial. En otras palabras, la aparición de esta tecnología nos permite pensar en la generación de modelos propios insertos en los centros educativos (Saorín et al., 2016) que también tengan su aplicabilidad en otros campos de conocimiento.

Esta intervención se realizó de forma experimental con el alumnado de sexto de Educación Primaria del centro escolar de Benifairó de la Valldigna. El objetivo fue trabajar el patrimonio local de una forma extensa y productiva, y configurar estos espacios como documentos para la investigación educativa e histórica. Aquí presentamos la intervención realizada y analizamos las ventajas que la fotografía estereoscópica puede aportar para el estudio del patrimonio desde un entorno educativo. 


\section{FUNDAMENTACIÓN TEÓRICA DE LA INTERVENCIÓN}

No podemos negar el boom tecnológico en el que nos encontramos inmersos, ya que "una característica de esta revolución es su capacidad de penetración en todos los dominios de la actividad humana" (Fernández-Lozano y Gutiérrez-Alonso, 2016, Martínez-López, 2009, p. 16). Así pues, la información impulsada por un desarrollo de las TIC basada en el conocimiento compartido y en los esfuerzos para convertir un gran volumen de datos en conocimiento accesible, lleva al surgimiento de nuevos espacios de comunicación y de transmisión de la información (Huerta, 2011). Este empleo de las TIC nos permite pasar de la sociedad de la información a la del conocimiento (Rojas-Sola, 2006, p. 664)

En esta realidad, y dentro de la escuela, aparece una dicotomía entre la imagen analógica y la digital. En las tareas escolares más vinculadas al positivismo y centradas en el grafocentrismo (Lisón, 2016), la imagen siempre ha estado en segundo plano, es decir, ha sido empleada como ornamento de un texto narrativo (Bel, 2017). Por el contrario, con el uso de las imágenes digitales se obtiene una mayor libertad de interpretación. Debido al uso frecuente de los dispositivos móviles por parte del alumnado, este ha desarrollado "una notable capacidad de construir y extraer significados complejos mediante el uso de fotografías" (Lisón, 2016, p. 157). Podemos así decir que los jóvenes entienden las tecnologías de la información y la comunicación "como si se tratase de una extensión natural de sus posibilidades ya que nacieron con ellas y las han utilizado prácticamente de manera intuitiva" (Huerta, 2011, p. 25). Por tanto, la alfabetización digital (Martínez-López, 2009) no se realiza en el aula, sino que se efectúa en otros entornos o contextos ya que, "la escuela sale de la escuela y se abre en el espacio y en el tiempo" (Lisón, 2016, p. 156).

Pese a todo, esta inserción es lenta por la escasa formación de los docentes (Fernández-Lozano y Gutiérrez-Alonso, 2016), o la visión que se tiene de unos dispositivos definidos como enemigos del aprendizaje y no como herramientas con gran potencial didáctico (Lisón, 2016).

Así pues, el principal freno del Mobile Learning y, con él, la negativa a ver todas las ventajas que presentan los dispositivos digitales para el trabajo del patrimonio, es el aprendizaje institucionalizado; una escuela tradicional donde la enseñanza de las diferentes áreas gira en torno al positivismo o la fuerte autoridad analógica "que frena[n] la introducción y desarrollo de una cultura escolar digital” (Lisón, 2016, p.160).

\subsection{Tecnología y Educación Patrimonial}

Las TIC han tenido un gran desarrollo en el procesamiento y divulgación de la enseñanza de la Historia y han facilitado la difusión del patrimonio cultural de todo el mundo, siendo los portales web, las aplicaciones para la tecnología móvil y la realidad virtual los principales vertebradores para la difusión de estos elementos materiales e inmateriales (Domènech, 2013; Tamayo y Leite, 2015). Todas las representaciones pueden ser visualizadas tanto en la web como en dispositivos portátiles como móviles o tablets (Caro, 2014, p. 667)

La web 2.0 como espacio que proporciona una participación masiva, permite a los distintos usuarios diseñar y crear sus propios contenidos para ser compartidos. Por tanto, estos entornos web posibilitan la "creación de un vínculo unívoco entre usuarios y editores" (Vicent, Rivero, y Feliu, 2015, p. 90). Claros ejemplos de todo ello son los blogs, las redes sociales (Facebook, Twitter, Instagram, YouTube...) o plataformas digitales que nos muestran mundos virtuales o que permiten la inserción de documentos históricos (Historypin, Opensimulator o Second Life). Esto ha generado entornos concretos como la reconstrucción de varios escenarios arqueológicos (Yacimiento Romano en Chipre elaborado por la Universidad de Pennsylvania o el Proyecto Okapi, una reconstrucción del poblado neolítico de Çatalhöyük por la Universidad de Berkeley). 
Junto a ello, contamos con proyectos museísticos como el centro experimental VIRGO, cuyas piezas arqueológicas están en visión estereoscópica o visión esférica $\left(360^{\circ}\right)$. En este proyecto, el usuario puede interactuar con la creación de etiquetas, escoger colores o seleccionar las vitrinas con el fin de crear su propio museo virtual. En todas estas plataformas, el alumnado puede interpretar de manera crítica todo lo que está experimentando y formar parte de las actividades didácticas propuestas por el docente (Vicent et al., 2015, p. 91).

Con la reconstrucción propuesta en entornos tecnológicos, se nos proporciona una herramienta para conocer el pasado de una manera comprensible, crítica y sensorial. La imagen inmersiva, como veremos más adelante, pone a prueba "la consistencia de la interpretación de los datos siendo esta uno de los grandes valores de la arqueología digital" (Vicent et al., 2015, p. 95).

Por otro lado, se deben dar una serie de características para la comprensión de estas imágenes inmersivas. Ha de existir un equilibrio entre dos partes. En primer lugar, la hipótesis de reconstrucción debe aparecer en su entorno o contexto y, en segundo lugar, se tiene que dar un contraste científico con la realidad arqueológica tal como lo establece la Carta de Londres para la visualización asistida por ordenador del patrimonio cultural, y los Principios de Sevilla publicados por la Asociación Española de Arqueología Virtual en 2012 (Vicent et al., 2015, p. 89). Un ejemplo de buena utilización lo encontraríamos en la Figura 1 donde podemos observar una hipótesis de reconstrucción del patio de armas del Castillo de Marinyén, una restauración digital, elaborada mediante software de edición gráfica a partir de la imagen equirectangular. Aquí podemos observar el nivel original del suelo, así como la cobertura del aljibe inferior de la fortaleza.

Por consiguiente, esta interactividad con este tipo de recursos estereoscópicos puede relacionarse claramente, como han destacado estudios recientes, con actividades de aprendizaje activo y con el desarrollo del pensamiento creativo (Rivero y Flores, 2013; Vicent et al., 2015).

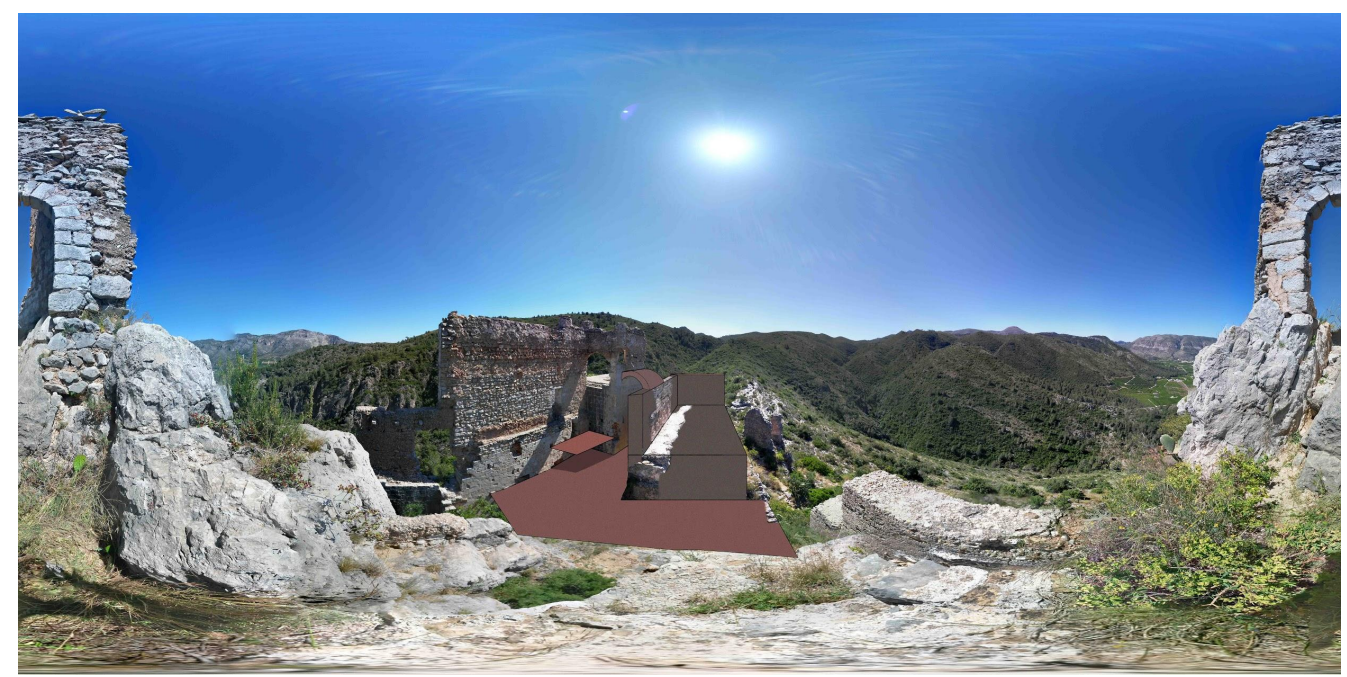

Figura 1. Hipótesis de reconstrucción del patio de armas y aljibe inferior del Castillo de Marinyén

La introducción de los distintos modelos de arqueología digital permite generar además imágenes en tiempo real, ya que el principal objetivo de esta tecnología es conseguir que el usuario se sienta ubicado dentro del modelo virtual. Este nuevo entorno está compuesto por un casco Helmet Mounted Display (HMD), un teléfono inteligente y un software (app) de simulación que permite la inmersión dentro de una realidad concreta generada por medio de fotografía estereoscópica. 
En esta experiencia la vista es el principal sentido sobre el que se actúa. De esta manera se quiebran los anteriores aprendizajes técnicos o tradicionales donde el modelo era el medio para generar la imagen, una imagen destinada a ser vista en una pantalla o impresa en papel. Son estos modelos creados a partir de la metáfora de Booker donde "los dibujos/imágenes son como ventanas a través de las cuales se ven las cosas" (Gutiérrez y Hernández, 2003, p. 5). En segundo lugar, esta tecnología permite alcanzar los niveles más elevados en la Taxonomía Cognitiva de Bloom -evaluar o crear-y, por último, implica una motivación para el alumno ya que "lo animará a continuar explorando el mundo virtual mientras aprende significativamente" (Vera et al., 2003, p. 6-9).

Por otra parte, y no menos importante, las presentaciones del patrimonio destinadas a educación generan un conocimiento directo, personal, subjetivo, y permiten una comprensión de elementos abstractos, hechos o fenómenos complejos (Vera et al., 2003). Es a partir de aquí de donde se desprende todo un mundo de aplicaciones e implicaciones que nos permiten conseguir un acercamiento al patrimonio arqueológico y cultural. Apps como la realidad aumentada (AR), proyecciones inmersivas, videojuegos, museos virtuales o geolocalización, así como aplicaciones para la toma y visionado de imágenes estereoscópicas hacen posible "una interactividad personalizada y una participación activa en el espacio virtualmente reconstruido" (Vicent et al., 2015, p. 90).

\subsection{Los panoramas estereoscópicos como modelos inmersivos para la Educación Patrimonial}

Los primeros modelos de fotografías esféricas los encontramos en Robert Barker, Joseph-Philibert Girault de Pangrey o Pascual Pérez y los hermanos Fárvaro, con ejemplos como la construcción de una estructura cilíndrica, techada, de catorce metros de diámetro y en cuya superficie interna se ubicaba una panorámica de la ciudad de Edimburgo, pasando por la primeras panografías utilizando placas de daguerrotipo (Cabezos-Bernal y Cisneros, 2016) o la invención del Calotipo por Henry Fox Talbot que permitía obtener copias para todo tipo de montajes. De hecho, podemos afirmar que "la fotografía panorámica es tan antigua como la misma fotografía” (Cabezos-Bernal y Cisneros, 2016, p. 71).

Esta técnica, denominada hoy fotografía estereoscópica, equirrectangular o esférica, es la que "supone un avance que complementa a los medios de representación arquitectónica tradicional y nos permite la visualización del espacio arquitectónico con una nueva dimensión" (Cabezos-Bernal y Cisneros, 2016, p. 80). Así pues, la imagen esférica, por ejemplo, en un entorno arqueológico, cubre un campo visual de $360^{\circ}$ en el eje de abscisas (eje X), y $180^{\circ}$ en el eje de ordenadas (eje Y). Por tanto, la imagen es una representación interactiva de un espacio 3D completo en otro 2D (AulaClic, 2017).

Ante esta nueva tipología de fotografía hemos de ser conscientes de sus limitaciones, así como de su problemática. Entre ellas encontramos: problemas de unión o cosido digital, la visualización, equipamiento, las distintas aplicaciones que nos permitirán la toma de la fotografía o los problemas en la composición de la imagen esférica.

Los problemas de unión o de cosido vienen generados por varias imágenes con zonas coincidentes. Es decir, una imagen (A) está parcialmente superpuesta sobre otra imagen (B) lo que genera un cruce entre las aristas de estas fotografías. A día de hoy existen diversos softwares de stitching o programas para el cosido digital como, por ejemplo: AutoPano, Giga, PtGui o Hugin. Todos ellos nos permiten crear panoramas sin ningún tipo de unión visible.

Si analizamos los problemas de visualización, tenemos que hacer referencia a multitud de software actualmente existente y que está a nuestra disposición. Cabe distinguir entre aquellos visores que son empleados para la visualización esférica en los ordenadores (PC), FSPViewer, o los estereoscópicos disponibles en los Smartphone, como por 
ejemplo VR Media Player. Todos ellos sitúan al usuario en el centro de la esfera virtual o punto nodal para combinar el panorama esférico y que cada ojo vea la imagen que le corresponde.

Otra problemática surge por el equipamiento. Este dependerá de con qué dispositivo ejecutamos la imagen de $360^{\circ}$. Si realizamos la misma con una cámara réflex nos hará falta un objetivo gran angular, trípode y también una rótula. Este último elemento es un brazo articulado que permite que la cámara gire alrededor de un punto fijo que coincide con el centro óptico de la lente, junto con un software de stitching. "Todo este equipamiento y software provoca que la fotografía esférica no sea tan sencilla como parece" (Cabezos-Bernal y Cisneros, 2016, p. 77).

Pese a todo, toda esta problemática tanto de unión, equipamiento o visualización casi desaparece si utilizamos un teléfono inteligente o Smartphone. Por tanto, "ni el coste ni la dificultad técnica suponen un impedimento para utilizar estos modelos en entornos educativos" (de la Torre-Cantero, Saorín, Meier, Melián-Díaz, y Drago-Díaz, 2015).

Disponemos de varias aplicaciones capaces de generar imágenes esféricas como: PhotoSphere o Google Street View que permiten la inserción en Google Maps. Sphere 360 genera el código de inserción para compartir las esféricas directamente desde nuestro teléfono a las redes sociales. En ese sentido resulta realmente interesante el aplicativo Google Camera.apk (extensión de Android). Este software es capaz de generar imágenes esféricas, coserlas automáticamente y guardarlas en la galería de nuestro dispositivo. Las imágenes ubicadas en la galería vienen en formato o extensión .jpg y son todas editables por software de edición gráfica como: Gimp, Paint o Photoshop. Al tratar estas imágenes con este tipo de programas, el editor separa los metadatos de la imagen y facilita la creación de una hipótesis de reconstrucción. Al terminar la edición y guardar la nueva imagen, el programa informático acopla a esta última sus metadatos volviendo a crear una imagen esférica. El nuevo panorama generado puede ser visionado con cualquier dispositivo HMD.

Por último, durante la ejecución de la imagen esférica, el principal problema radica en el giro. Al rotar sobre nosotros mismos a la vez que tomamos las distintas capturas del entorno arqueológico, nuestro cuerpo se desplaza ligeramente. Este desplazamiento, también llamado error de paralaje o parallax effect (Cabezos-Bernal y Cisneros, 2016), provoca que la última imagen no encaje con la primera. Son dos las soluciones a este problema. En primer lugar, se puede usar un trípode junto con una sujeción para el móvil, por ejemplo, el soporte de un palo selfie. Si esto no es factible, podemos fijarnos en un punto fijo del suelo (una piedra o algún elemento que destaque). Aun así, el software puede absorber un pequeño error de paralaje y ser corregido con los actuales editores gráficos (Figura 2). Sin embargo, existen situaciones en las que este desplazamiento es tan grave que Google Camera es incapaz de corregirlo, por lo que la toma de imágenes debe repetirse (Figura 3).

\section{OBJETIVOS Y DESARROLLO DE LA INTERVENCIÓN}

Teniendo en cuenta las consideraciones anteriores, planteamos una propuesta de intervención educativa para sexto de Primaria dividida en varias actividades y sesiones que se detallan a continuación.

En cuanto al contexto sociocultural de la intervención escolar, se realizó con alumnado de un centro escolar de Benifairó de la Valldigna (comarca de La Safor-Valldigna) con acceso a este tipo de dispositivos.

Nuestra propuesta de intervención pretende que los alumnos y alumnas conozcan y valoren la historia de su entorno social a través de la observación inmersiva y el análisis de un espacio patrimonial determinado con fotografía estereoscópica. En cuanto a la perspectiva científica, el alumnado actúa como investigador sobre la Edad Media y 


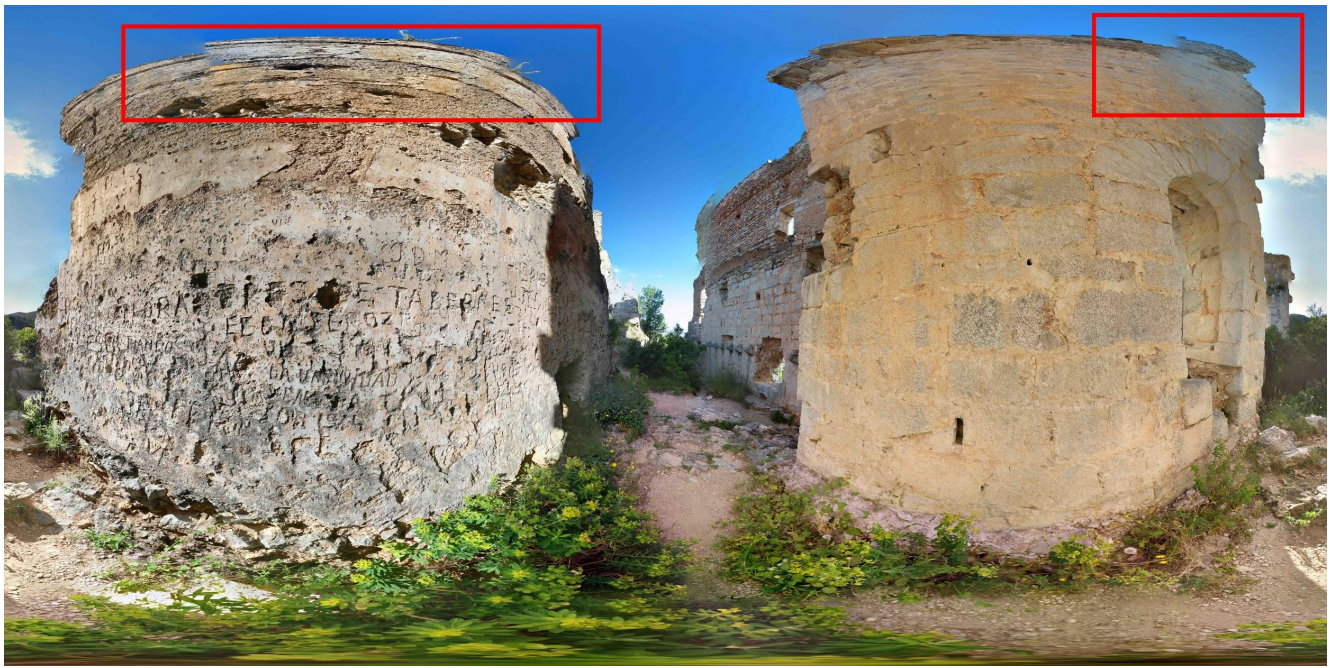

Figura 2. Se pueden observar errores de paralaje suaves tanto en el borde superior derecho como izquierdo fruto de un desplazamiento mínimo en la toma. Dichos errores no afectan mucho la integridad de la imagen esférica

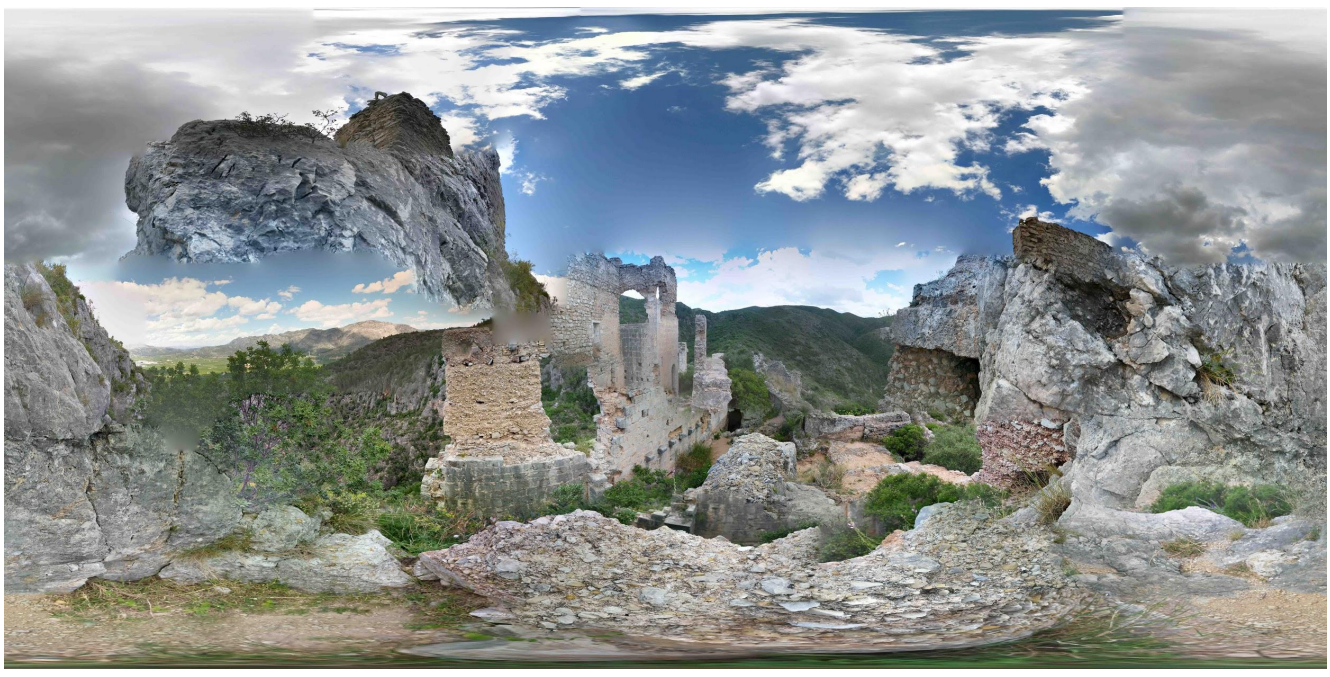

Figura 3. En esta imagen se observa un error de paralaje aberrante. El desplazamiento en la toma es tan grande que el software no es capaz de coser en orden los distintos panoramas que conforman la imagen esférica $y$, por tanto, la imagen debe repetirse

el Castillo de Marinyén, espacio que permite ampliar aspectos de los referidos en los contenidos curriculares clásicos. Así, una buena parte de la propuesta didáctica va dirigida a conocer la singular castellología de esta fortaleza, así como la creación de un vuelo virtual y una hipótesis de reconstrucción del Patio de Armas de este castillo.

Por último, en el ámbito psicopedagógico hay que tener en cuenta la atención a la diversidad. De hecho, los materiales están elaborados teniendo en cuenta las características del grupo. Como a continuación se podrá observar, los recursos que se presentan son variados, y trabajan todas las competencias clave (Tabla 1), así como las diferentes habilidades, estándares de evaluación e indicadores de logro apuntadas por el Decreto 108/2014, del 4 de julio, del Consell (GVA, 2014).

A partir de las premisas anteriores que reafirman el uso de la imagen esférica para el estudio de elementos arqueológicos de manera inmersiva, se diseñaron diferentes etapas que dan pie a una intervención didáctica en este espacio patrimonial. Estas consistieron en: 
1. Investigar el yacimiento arqueológico a partir de una fuente secundaria para crear un conocimiento crítico.

2. Separar cada estructura que conforma la castellología para repartirlas en grupos (albacara, celoquia o torre del homenaje y recinto norte).

3. Elaborar las distintas imágenes esféricas de cada estructura por medio del Smartphone.

4. Exposición crítica de cada estructura mediante la pizarra digital y uno o varios dispositivos HMD.

5. Creación de un vuelo virtual por medio de la aplicación web Paneek-free $360^{\circ}$ virtual tour software.

6. Establecimiento de una hipótesis de reconstrucción, a partir de la imagen esférica de la celoquia o parte más alta del castillo. Seguidamente, su elaboración mediante el editor gráfico Gimp.

Estas fases se concretaron en las siguientes actividades o sesiones de trabajo desarrolladas a continuación:

En un primer momento (Actividad 1) y para investigar el yacimiento arqueológico, se partió de una fuente secundaria como es el documento publicado por el Centre Excursionista de Tavernes de la Valldigna en la revista DYA con motivo de su aniversario (Martínez y Gallart, 1998). Dicho texto versa sobre la historia de la fortaleza, así como de su singular castellología. Para ejecutar esta actividad se dividió el aula en tantos grupos como elementos del castillo se deseaba explorar. Posteriormente, y con la ayuda del procesador de textos, se digitalizó el documento, que sirvió para ser expuesto durante la presentación de otra actividad. Esta fuente se relacionó, a su vez, con otras que el alumnado localizó en la red y que sirvieron para completar la descripción de otros elementos de la castellología descrita en la actividad.

En un segundo momento (Actividad 2) y dentro del marco de una actividad de aprendizaje servicio, se realizó una visita al Castillo de Marinyén, declarado Bien de Interés Cultural (BIC) en 2002 (Conselleria d'Educació, 2015) y que es uno de los elementos patrimoniales más significativos de Benifairó de la Valldigna. Una vez en el yacimiento arqueológico, cada grupo, acompañado por un miembro del Centre Excursionista de Tavernes de la Valldigna (CETV), realizó varias imágenes esféricas de la parte del monumento que hubieron de exponer posteriormente en clase.

En un tercer momento (Actividad 3), ya en el aula y con los resúmenes impresos, cada grupo expuso la imagen esférica del elemento de la castellología que analizó. Las imágenes esféricas de todos los grupos se proyectaron en la pizarra digital empleando el software FSPviewer. Al mismo tiempo, otro o varios miembros de un grupo distinto, dependiendo de la cantidad de HMD con los que se contaba, experimentaron la inmersión en VR en dicho elemento arqueológico.

En un cuarto momento (Actividad 4), con todas las imágenes esféricas volcadas en una carpeta y ubicadas en cada PC del aula de informática del centro escolar, se procedió al montaje del vuelo virtual. Para tal fin, se recurrió a la aplicación web de Paneek-free $360^{\circ}$ virtual tour donde se contaba con todas las herramientas necesarias para la creación de estos paseos virtuales (Figura 4). Al finalizar el diseño, se decidió ceder estos recursos al Ayuntamiento de Benifairó de la Valldigna para que pudieran publicarlos en su web institucional y pudieran servir de reclamo turístico de la localidad.

Finalmente, se planteó la posibilidad de realizar una hipótesis de reconstrucción a partir de la imagen estereoscópica (Actividad 5). Para poder crear esta hipótesis es necesario que la imagen esférica cumpla unos criterios mínimos que no compliquen al alumnado durante el dibujo de la perspectiva. Por ejemplo la imagen debe ser 


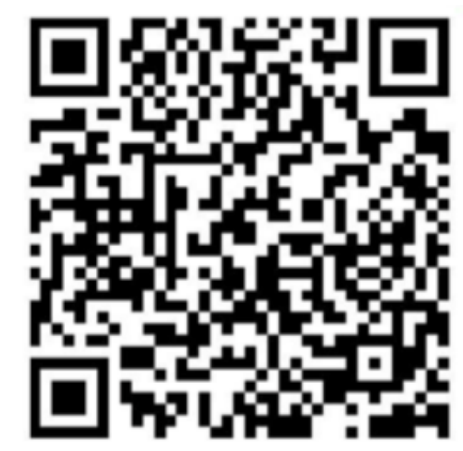

Figura 4. Código QR de la demostración del vuelo virtual en el castillo de Marinyén

equirrectangular y ha de poseer un campo de trabajo casi sin perspectiva. Una vez elegida la imagen adecuada se procedió al dibujo de la hipótesis de reconstrucción utilizando el editor gráfico Gimp. En nuestro caso, la conjetura recreó el nivel original del patio de armas o celoquia que los alumnos habían visitado y documentado. Los resultados de esta intervención didáctica pueden consultarse en la siguiente página web: https://sites.google.com/view/castillodemariyen

Tabla 1. Relación entre las diferentes etapas de la intervención didáctica y competencias básicas en el marco curricular del Decreto 108/2014 (GVA, 2014)

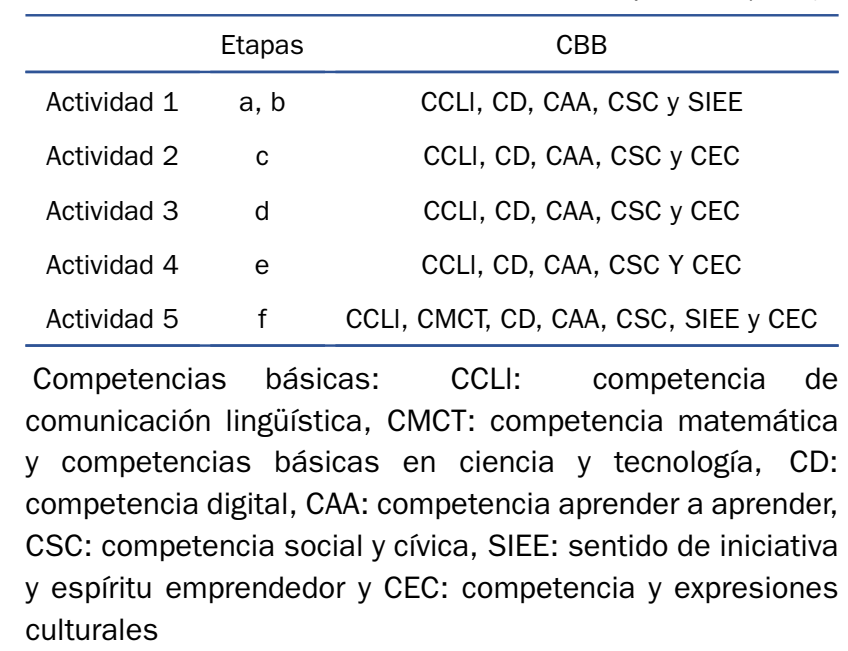

\section{CONCLUSIONES}

En el presente trabajo hemos presentado las ventajas de la inserción de la tecnología digital para el trabajo del patrimonio material e inmaterial a partir de la introducción de la fotografía estereoscópica o esférica en la línea de lo sugerido por proyectos y planes nacionales de trabajo de los recursos patrimoniales como el PNEyP.

La escuela tradicional realiza, como hemos constatado, una utilización pobre de la imagen como recurso o documento útil para la enseñanza. En todos los casos se prioriza el texto narrativo por encima de esta. En un tipo de aprendizaje memorístico, la imagen adopta un papel decorativo y, si analizamos el tratamiento del patrimonio, este es trabajado de manera anecdótica y siempre sujeto a contenidos más generales.

Por ello, es necesario un cambio de metodología para elaborar unidades, propuestas o programaciones didácticas diferentes. Tomando en consideración que el alumnado presenta una mayor alfabetización digital que el docente, en muchas ocasiones, desarrollada fuera de la escuela con varios dispositivos electrónicos como tablets, telé- 
fonos inteligentes u ordenadores; podemos aprovechar la educación patrimonial para mejorar esa alfabetización digital en un uso correcto de las TIC, trabajar en equipo, proceder a la selección y discriminación de múltiple información, así como en el diseño de recursos para ser compartidos globalmente.

En el siglo XXI casi todo el mundo dispone de un móvil, un dispositivo con un enorme potencial educativo, un aparato con calculadora, cámara fotográfica y de vídeo, grabadora de sonidos, y una infinidad de aplicaciones (incluyendo las educativas) que, si no se tienen, se pueden descargar. Por tanto, ¿por qué no introducir estos dispositivos en el aula?

Analizadas las potencialidades del Mobile Learning en la educación patrimonial por medio de la intervención didáctica aquí descrita, hemos podido afirmar, por tanto, que el trabajo sobre el patrimonio puede orientarse hacia una manera creativa, cumpliendo así los objetivos del PNEyP e incorporando la inmersión virtual. La fotografía estereoscópica, por su fácil creación y manejo, puede ser una herramienta de interés en ese avance pues posibilita conocer el pasado de una manera comprensible, crítica y sensorial. Esto, además, puede suponer el trabajo de aspectos cercanos que nutran otras esferas económicas y sociales de la localidad (como puede ser el turismo), algo que ya ha sucedido en los entornos urbanos (Jung y Han, 2014). Por medio de la inmersión virtual se consiguen resultados óptimos en el trabajo con el patrimonio y se desarrolla el trabajo sobre contenidos curriculares de forma novedosa y creativa (Vicent et al., 2015).

Con una tecnología de fácil acceso se facilita que el aprendizaje del alumno sea significativo y, además fomenta la motivación para continuar explorando todo lo que le rodea reforzando la figura del maestro/a (Haddad, 2016). De hecho, gracias a esta tecnología podemos reforzar la figura del docente en el aula. Si bien es cierto que el profesorado en educación patrimonial es visto como un acompañante y no como un agente activo protagonista, con las nuevas tecnologías los docentes son capaces de transformar el aula en un museo virtual y, con el acompañamiento en la creación de contenidos, pueden ayudar en el desarrollo del aprendizaje dentro de contextos digitales diversos.

\section{REFERENCIAS}

Arévalo, B., Bayona, E., y Rincón, I. R. (2015). Metodología para documentación 3D utilizando fotogrametría digital. Tecnura, 19, 113-120.

http://dx.doi.org/10.14483/udistrital.jour.tecnura.2015.3.a09

AulaClic. (2017). Photo Sphere. La fotografía esférica $360^{\circ}$ con Android. AulaClic, 31, 1-6. Descargado de https://www.aulaclic.es/android/fotografia/fotos-esfericas_1.html

Bel, J. C. (2017). Imagen y libros de texto de Historia en Educación Primaria: estudio comparativo a partir de un análisis cualitativo. Revista de Educación, 377, 82-112. http://dx.doi.org/10.4438/1988-592X-RE-2017-377-354

Cabezos-Bernal, y Cisneros, J. (2016). Panoramas esféricos estereoscópicos. EGA Revista de Expresión Gráfica Arquitectónica, 21(28), 70-81. https://doi.org/10.4995/ega.2016.6264

Calderón, B. (2015). La importancia de la Historia en la educación patrimonial: Herramientas didácticas para la atribución de valores al patrimonio urbano. , 41. Descargado de http://clio.rediris.es/n41/articulos/calderon2015.pdf

Caro, J. L. (2014). Fotogrametría digital para la difusión del patrimonio numismático. $X V$ Congreso Nacional de Numismática, Madrid, 28-30 octubre (pp. 669-676). Descargado de http://www.man.es/man/dms/man/actividades/congresos-reuniones/2014/ congreso-numismatica/actas/2016_XVCNN_Caro.pdf

Carretero, M. (2007). Documentos de identidad. La construcción de la memoria histórica en un mundo global. Barcelona: Paidós. 
Castañeda, L., Esteve, F., y Adell, J. (2018). ¿Por qué es necesario repensar la competencia docente para el mundo digital? RED. Revista de Educación a Distancia, 56. http://dx.doi.org/10.6018/red/56/6

Conselleria d'Educació. (2015). Bens d'Interés Cultural. Descargado de http://www.ceice.gva.es/web/patrimonio-cultural-y-museos/bics

de la Torre-Cantero, J., Saorín, J. L., Meier, C., Melián-Díaz, D., y Drago-Díaz, M. (2015). Creación de réplicas de patrimonio escultórico mediante reconstrucción 3D e impresoras 3D de bajo coste para uso en entornos educativos. Arte, individuo y Sociedad, 27(3), 429-446. https://doi.org/10.5209/rev_ARIS.2015.v27.n3.45864

Domènech, J. (2013). Los museos virtuales como recurso didáctico. Construyendo puentes digitales entre el museo y el aula.@ TIC revista d'innovació educativa, 10, 92-100. https://doi.org/10.7203/attic.10.2102

Fernández-Lozano, J., y Gutiérrez-Alonso, G. (2016). Aula 3.0: Una nueva forma de aprender geología. El uso de las apps Trnio y Skechfab para construir modelos. Enseñanza de las Ciencias de la Tierra, 24(2), 163-168. Descargado de https://www.raco.cat/index.php/ECT/article/view/312550/402625

Fontal, O., y Ibáñez, A. (2015). Estrategias e instrumentos para la educación patrimonial en España. Educatio Siglo XXI, 33(1), 15-32. Descargado de https://revistas.um.es/educatio/article/view/222481

Gutiérrez, D., y Hernández, L. A. (2003). Potencial de la Realidad Virtual en el ámbito del Patrimonio. Revista PH, 11(46), 95-101. https://doi.org/10.33349/2003.46.\%20Especi.1629

GVA. (2014). Decreto 108/2014, de 4 de julio, del Consell, por el que se establece el currículo y desarrolla la ordenación general de la educación primaria en la Comunitat Valenciana. Descargado de https://www.dogv.gva.es/portal/ficha_disposicion_pc.jsp?sig=006087/2014\&L=1

Haddad, N. (2016). Multimedia and cultural heritage: a discussion for the community involved in children's heritage edutainment and serious games in the 21st century. Virtual Archaeology Review, 7(14), 61-73. https://doi.org/10.4995/var.2016.4191

Huerta, R. (2011). Maestros y museos. Valencia: Publicaciones de la Universitat de València.

Jung, T., y Han, D. (2014). Augmented Reality (AR) in Urban Heritage Tourism. e-Review of Tourism Research, 5. Descargado de https://e-space.mmu.ac.uk/id/eprint/608512

Lisón, J. (2016). Cultura escolar, móviles y fotografía digital. Encounters on Education, 17, 142-162. https://doi.org/10.24908/eoe-ese-rse.v17i0.6316

Martínez, J., y Gallart, M. (1998). El Castell d'Alfàndech de Marinyén. Revista DYA, 5, 71-82.

Martínez-López, F. (2009). Las tecnologías de la información y la comunicación (TIC) y las competencias básicas en educación. Espiral. Cuadernos del profesorado, 2(3), 15-26.

Pinto, H., y Molina, S. (2015). La educación patrimonial en los currículos de ciencias sociales en España y Portugal. Educatio Siglo XXI, 33(1), 103-128.

https://doi.org/10.6018/j/222521

Rivero, P., y Flores, H. (2013). Potencialidad didáctica del generador de exposiciones virtuales VIRGO (Virtual Generator and Organizator). XXIV Simposio Internacional de Didáctica de las Ciencias Sociales "Medios de comunicación y pensamiento crítico. Nuevas formas de interacción social”. Guadalajara.

Rojas-Sola, J. I. (2006). Patrimonio cultural y tecnologías de la información: propuestas de mejora para los museos de ciencia y tecnología y centros interactivos de venezuela. Interciencia, 31(9), 664-670. Descargado de http://www.scielo.org.ve/ scielo.php?script=sci_arttext\&pid=S0378-18442006000900009\&lng=es\&tlng=es

Santacana, J., Martínez, T., López, V., y Grevtsova, I. (2015). Aplicación de la investigación arqueológica para el diseño de recursos educativos de base virtual en la didáctica del patrimonio. Enseñanza de las ciencias sociales: revista de investigación. Enseñanza de las ciencias sociales: revista de investigación, 14, 27-38.

http://dx.doi.org/10.1344/ECCSS2015.14.3 
Saorín, J. L., Meier, C., Ruiz, C., Torre-Cantero, J. D. L., Melián, D., y Bonnet, A. (2016). Creación, visualización e impresión 3D de colecciones online de modelos educativos tridimensionales con tecnologías de bajo coste; caso práctico del patrimonio fósil marino de Canarias. Education in the Knowledge Society, 17(3), 89-108.

http://dx.doi.org/10.14201/eks201617389108

Tamayo, C., y Leite, E. (2015). Las tecnologías de la información y las comunicaciones como herramientas para la gestión del patrimonio cultural con una visión emprendedora. Holos, 8, 290-303. https://doi.org/10.15628/holos.2015.3660

UNESCO. (2003). Indicaciones generales para la sostenibilidad del patrimonio. Descargado de https://es.unesco.org/creativity/sites/creativity/files/digital-library/cdis/Patrimonio.pdf

Vera, G., Ortega, J. A., y Burgos, M. A. (2003). La realidad virtual y sus posibilidades didácticas. Revista científica electrónica de Educación y Comunicación en la Sociedad del Conocimiento, 2(2), 1-17. Descargado de

http://www.ugr.es/ sevimeco/revistaeticanet/Numero2/Articulos/Realidadvirtual.pdf

Vicent, N., Rivero, P., y Feliu, M. (2015). Arqueología y tecnologías digitales en Educación Patrimonial. Educatio Siglo XXI, 33(1), 83-102. https://doi.org/10.6018/j/2225117

Yovcheva, Z., Buhalis, D., Gatzidis, C., y Elzakker, C. (2014). Empirical evaluation of smartphone augmented reality browsers in an urban tourism destination context. International fournal of Mobile Human Computer Interaction, 6(2), 10-31.

https://doi.org/10.4018/ijmhci.2014040102 